\title{
Farklı Değişkenler Kullanılarak Yapı Performans Puanın Hesaplanması
}

\author{
Ercan IŞIK ${ }^{1 *}$, Zuhal TOZLU² \\ ${ }^{1}$ Bitlis Eren Üniversitesi, Mühendislik-Mimarlık Fakültesi, İnşaat Mühendisliği, Bölümü, Bitlis \\ ${ }^{2}$ Çevre ve Şehircilik Bakanlı̆̆l, Altyapı ve Kentsel Dönüşüm Hizmetleri Genel Müdürlüğ̈̈, Ankara
}

\begin{abstract}
Özet
Yaşanılan depremlerin acı tecrübeleri ışı̆̆ında ülkemizde bulunan yapı stokunun büyük bir kısmının depreme duyarlı olmadığı görülmektedir. Mevcut yapı stokunun fazla olması, zaman ve eleman yetersizliği gibi ana sebeplerden dolayı deprem zararlarını en aşağı seviyelere indirgemek için mevcut yapılar üzerinde oldukça hızlı değerlendirme yöntemlerini uygulama zorunluluğu ortaya çıkmıştır. Kademeli olarak değerlendirilecek binaların risk önceliklerinin belirlenmesi, her aşamada incelenecek bina sayısında bir azalma meydana getirecektir. $\mathrm{Bu}$ hızlı yöntemlerin bir amacı da detaylı analize tabi tutulması gereken yapı sayısını en aza indirgemektir. Birinci aşama değerlendirmede detaylı bir bilgiye ihtiyaç duyulmamaktadır. Bu değerlendirme aşamasında yapının dışarıdan ve kısmen de yapı içerisinden deprem davranışını etkileyecek bilgilerin toplanması ile değerlendirme yapılabilmektedir. Literatürde yapıların birinci aşama değerlendirmesi ile ilgili değişik yöntemler bulunmaktadır. Çevre ve Şehircilik Bakanlığı tarafindan 2013 yılında yayımlanan yönetmelikle bu yöntemlerin yönetmeliğe girmesi sağlanmıştır. Bu çalışmada, 2013 yılında yürürlüğe giren riskli yapıların tespit edilmesine ilişkin esaslar kısmında yer alan birinci aşama değerlendirme yöntemi kullanılarak mevcut beş katlı bir betonarme yapı için zemin sınıfları, taşıyıcı sistem türü ve görünen yapı kalitesi parametreleri değişken olarak seçilmiş ve bu değişkenlere göre bina performans puanları hesaplanmıştır. Hesaplanan performans puanları karşılaştırılmış ve seçilen değişkenlerin yapı performans puanları üzerindeki etkileri yorumlanmıştır.
\end{abstract}

Anahtar Kelimeler: Betonarme, birinci aşama, zemin sınıfı, görsel kalite

\section{Calculation of Building Performance Score by Using Different Variables}

\begin{abstract}
Under the light of unpleasant experience we got through earthquakes, we observe that most of the structure reserves in our country are not durable to earthquake. Because of the main reasons such as having too many building stocks and insufficiency of time and staff, in order to minimize earthquake damages, the requisite of applying rapid assessment methods for existing structures has emerged. Determining risk priorities of the structures to be evaluated gradually will cause a decrease in the number of analyzed structures in every stage. Another aim of these rapid methods is to minimize the number of structures to be analyzed in detail. In the first stage evaluation, detailed information is not necessary. In this evaluation stage, the evaluation can be carried out through collecting the information affecting earthquake behavior from outside and partly inside the structure. There are various methods about the first stage assessment of the structures in literature. Via a regulation made by Ministry of Environment and Urbanization in 2013, these methods took part in the regulations. In this study, the soil classes, the type of structural system and the visual quality of structure parameters have been chosen as variants through using the first stage assessment method mentioned in the rules related to obtain the risky structures came into force in 2013 and structure performance scores have been calculated according to these variants. These scores have been compared and the effects of the chosen variants on structure performance scores have been commented.
\end{abstract}

Keywords: Reinforced concrete, first stage, soil class, visual quality

\footnotetext{
"SorumluYazar: eisik@beu.edu.tr
} 


\section{Giriș}

Yapıların deprem güvenliğinin belirlenmesinde asıl amaç mevcut yapılarda gerekli inceleme ve hesapların olası bir depremden önce yapılarak mevcut yapı stoku hakkında doğru kararlar verilmesini sağlamaktır. Mevcut yapı stokunun fazla olması, yapılar üzerindeki değerlendirmeyi zaman, nitelikli eleman yetersizliği ve ekonomik açıdan güçleştirmektedir. Herhangi bir yapının deprem güvenliğinin detaylı olarak incelenmesi bile günler boyunca sürmektedir. Dolayısıyla mevcut her yapının detaylı olarak incelenmesi mümkün görünmemektedir. Bu bağlamda yapıların değerlendirilmesinde daha hızlı ve doğru sonuçlar verecek yöntemler kullanılarak doğru sonuçlara ulaşılabilmektedir. Bu yöntemler genel olarak birinci aşama değerlendirme yöntemi olarak adlandırılmaktadır. $\mathrm{Bu}$ yöntemler kullanılarak risk önceliği olan binalar belirlenebilmektedir. Bu da detaylı analize tabi tutulacak bina sayısında büyük oranda azaltma meydana getirecektir.

Yapıların aşamalı olarak değerlendirilmesi ile ilgili literatürde değişik yöntemler bulunmaktadır. Çevre ve Şehircilik Bakanlığı tarafından 2013 yılında yayımlanan yönetmelikte riskli binaların belirlenmesi ile ilgili birinci aşama değerlendirme yöntemi yasal bir zemine oturtulmuştur [1]. Bu yönetmelikte, yapıların birinci aşama değerlendirme yönteminde dikkate alınacak parametreler ve performans puanlarının nasıl hesaplandığı ortaya konulmuştur.

Yapıların savunmasızlığı arttıkça doğal afetlerin (deprem, sel vb.) oluşturacağı hasar miktarı da artacaktır. Doğal afetlerin büyüklüğü ve yapıların yeterli düzeyde güvenliğinin sağlanmamış ve yönetmeliklerde belirtilen şartlara uygun yapılmamış olması yani olumsuz yapı özellikleri de oluşabilecek zararı doğrudan etkileyecektir [2].

Bu çalışmada, 2013 yılında yürürlüğe giren Afet Riski Altındaki Alanların Dönüştürülmesi Hakkındaki Kanunun Uygulama Yönetmeliğinde yer alan riskli yapıların tespit edilmesine ilişkin esaslar kısmında yer alan birinci aşama değerlendirme yöntemi kullanılarak mevcut bir betonarme ve bir yığma yapının performans puanları hesaplanmıştır. $\mathrm{Bu}$ çalışma, yapılacak birinci aşama değerlendirme yönteminin yapılara nasıl uygulanması gerektiği ve dikkate alınması gereken parametreler hakkında bilgi vermektedir.

\section{Materyal ve Yöntem}

Deprem performans1, belirli bir deprem etkisi altında bir binada oluşabilecek hasarların düzeyi ve dağılımına bağlı olarak belirlenen yapı güvenliği olarak tanımlanmaktadır [3].

Yapıların deprem güvenliğinin belirlenmesinde asıl amaç, mevcut yapılarda gerekli inceleme ve hesapların olası bir depremden önce yapılarak yetersiz görülen yapıların depremde hedeflenen performans seviyesine yükseltilmesi için uygulanacak iyileştirme işlemlerine karar verilmesidir. Deprem tehlikesi altında olan kentsel yerleşimlerde yeterli deprem güvenliğine sahip olmayan pek çok yapı olduğu bilinmektedir.

Yapı hasarlarının, yapının özelliklerine göre değiştiği çok iyi bilinen bir gerçektir. Ancak, bu özelliklerin ortaya konması, yapıların sınıflandırılması sonucunda elde edilen verilerin değerlendirilmesi koşulu ile gerçekleşebilmektedir. Bu bağlamda riskli binaların tespit edilmesi önem arz etmektedir.

Riskli bina, yapının bulunduğu bölge için Türk Deprem Yönetmeliği (TDY 2007)'nde verilen tasarım depremi altında yıkılma veya ağır hasar görme riski bulunan bina olarak tanımlanmaktadır [1]. TDY2007'ne göre bir yapının deprem performansının belirlenmesinde kullanılacak talep spektrumu, yönetmeliğin ikinci bölümünde verilen tasarım (50 yılda aşılma olasılığ $\% 10$ olan depremler) spektrumudur [4]. 


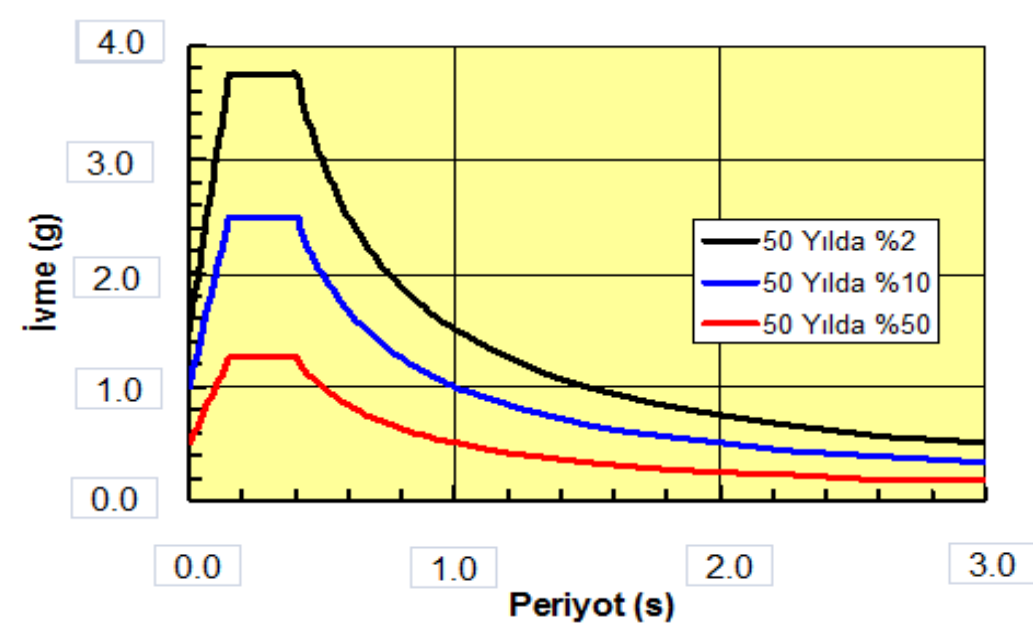

Şekil 1. Farklı deprem aşılma olasılıkları için spektrum eğrileri

Aynı zamanda riskli alan içinde veya dışında olup ekonomik olarak ömrünü tamamlamış olan, yıkılma veya ağır hasar görme riski taşıdığı bilimsel ve teknik verilere dayanılarak tespit edilen binalarda riskli bina olarak tarif edilmektedir [5].

Bakanlık tarafından yayınlanan kanun kapsamında belirli alanlarda önceliklerin ve riskli olabilecek binaların bölgesel dağılımının belirlenmesi amacıyla, bina özelliklerini ve deprem tehlikesini göz önüne alan birinci aşama değerlendirme yöntemleri kullanılabilir. Yapılacak sıralamanın daha hassas olması istenirse, ikinci aşama değerlendirme yöntemleri de kullanılabilir.

Düşük riskli çıkan binaların deprem yönetmeliğine uygun olup olmadığı kesin bir dille söylenemez. Yukarıda belirtildiği gibi bu sadece birinci aşama değerlendirmedir. Dolayısıyla kesin sonuçlar ancak kesin analiz yöntemleri sonucunda ortaya çıkacaktır. Bu yöntem sadece ikinci aşama değerlendirme yönteminde incelenecek binaların önceliğinin belirlenmesi amacını taşımaktadır.

\subsection{Betonarme Binalar için Birinci Aşama Değerlendirme Yöntemi}

Bu yöntem 1-7 katlı mevcut betonarme binalar için kullanılabilir. Yöntemin kullanılabilmesi için gerekli olan parametreler aşağıda verilmektedir:

- Taşıyıcı sistem türü

- Kat adedi

- Mevcut durum ve görünen kalite

- Yumuşak kat/zayıf kat

- Düşeyde düzensizlik

- Ağır çıkmalar

- Planda düzensizlik/Burulma etkisi

- Kisa kolon etkisi

- Yapı nizamı/Çarpışma etkisi

- Tepe/yamaç etkisi

- Deprem tehlikesi ve zemin sinifi

Taşıyıcı sistem türü, betonarme çerçeve (BAÇ) ile betonarme çerçeve ve perde (BAÇP) olmak üzere iki farklı tür tarif edilmiştir. Kat adedi olarak temel üzerindeki kat sayısı dikkate alınmaktadır. Kademeli yapılarda en fazla kat adedine sahip kısım dikkate alınır.

Yapıdaki herhangi bir katın, rijitliğinin ve dayanımının diğer katlara oranla belirgin şekilde az olması, yumuşak kat kavramını meydana getirmektedir. Zemin katın ticari amaçlarla kullanılması nedeniyle birçok binada zemin kat rijitliği üst katlara göre küçük kalmakta ve "yumuşak kat" 
oluşmaktadır. Yapıya gelen deprem kuvvetlerinin tüm katlara kat döşemesi hizasında etkidiği farz edilmektedir ve yapının yapacağı toplam deplasman toplam kat yüksekliği boyunca bölüşülmek yerine rijitliği az olan kat diğer katlara göre daha fazla deplasman yapmakta ve o kat yumuşak kat olarak adlandırılmaktadır [6]. Ayrıca dolgu bölme duvarları olmayan binalardaki giriş katları, yanal ötelenmeler bakımından, üst katlara nazaran göreceli olarak önemli ölçüde zayıf kalmaktadır [7].

Binaların çerçeve sistemleri dışında yapılmış özellikle ağır parapetli balkonlar ya da çıkmalar bina kütlesinde düzensizlik meydana getirmektedir. Zemin katında çekme bırakılan binalar da ağır çıkmalar sınıfına girmektedir. Bu tür çıkmalar binalarda kütle merkezi değişim gösterdiğinden bina üzerinde meydana gelen deprem etkisi de artmaktadır ve deprem sonrası hasarlı binalarda ağır çıkmaların etkisi olduğu görülmüştür [8].

Planda düzensizlik, planın geometrik olarak simetrik olmaması ve düşey yapısal elemanların düzensiz yerleştirilmesi olarak tanımlanır [5]. Betonarme perdelerin konumları da burulma düzensizliği olarak tanımlanır [9].

Betonarme çerçevelerin yarım yükseklikte bölme duvarlarla doldurulması, bant pencere oluşturulması, merdiven sahanlıklarında ara kirişler kullanılması kısa kolon oluşumunun başlıca nedenleridir [10]. Kısa kolonun oluşmasına neden olan başlıca faktörler asma katlar, mekanik katlar, eğimli arsa, kademeli temel, kolona bitişik açıklıklar ve merdiven sahanlığı olarak sayılabilir [11].

Binanın belirgin olarak bir tepe üstünde olması veya yüksek eğimli $\left(30^{\circ}\right.$ den fazla) bir yamaçta bulunması, maruz kalacağı veya kaldığı deprem etkilerini bir miktar arttırmaktadır. Sokaktan kolayca gözlemlenebilen bu durum yapı deprem puanı hesaplanırken dikkate alınmalıdır [12].

Bitişik binaların konumları deprem performansını çarpışma nedeniyle etkileyebilmektedir. Kenarda yer alan binalar bu durumdan olumsuz etkilenmekte, bitişik bina ile kat seviyeleri farkliysa bu olumsuzluk daha da artmaktadır. Çarpışma etkisinin söz konusu olduğu durumlar dışarıdan yapılacak gözlemler ile belirlenecektir [1].

Yerel zemin koşullarının sismik hareketlerin karakterlerini doğrudan etkilediği ve değiştirdiği, bu zeminler üzerindeki mevcut yapılar üzerinde hasara sebep olabileceği bilinen bir gerçektir [13]. Deprem tehlikesi ve zemin sınıfı da dikkate alınacak parametrelerden bir diğeridir. Zemin sınıfları Tablo 1'de gösterilmiştir [4].

Tablo 1. Yerel zemin siniflar1 [4]

\begin{tabular}{|c|l|}
\hline $\begin{array}{c}\text { Yerel Zemin } \\
\text { Simufi }\end{array}$ & $\begin{array}{c}\text { Zemin Grubu ve } \\
\text { En Üst Zemin Tabakast Kalınlğı }\left(\mathrm{h}_{1}\right)\end{array}$ \\
\hline $\mathrm{Z} 1$ & $\begin{array}{l}\text { (A) grubu zeminler } \\
h_{1} \leq 15 \mathrm{~m} \text { olan }(\mathrm{B}) \text { grubu zeminler }\end{array}$ \\
\hline $\mathrm{Z} 2$ & $\begin{array}{l}h_{1}>15 \mathrm{~m} \text { olan }(\mathrm{B}) \text { grubu zeminler } \\
h_{1} \leq 15 \mathrm{~m} \text { olan }(\mathrm{C}) \text { grubu zeminler }\end{array}$ \\
\hline $\mathrm{Z} 3$ & $\begin{array}{l}15 \mathrm{~m}<h_{1} \leq 50 \mathrm{~m} \text { olan }(\mathrm{C}) \text { grubu zeminler } \\
h_{1} \leq 10 \mathrm{~m} \text { olan (D) grubu zeminler }\end{array}$ \\
\hline $\mathrm{Z} 4$ & $\begin{array}{l}h_{1}>50 \mathrm{~m} \text { olan (C) grubu zeminler } \\
h_{1}>10 \mathrm{~m} \text { olan (D) grubu zeminler }\end{array}$ \\
\hline
\end{tabular}

Yap1 ile ilgili toplanacak veriler ile betonarme binaya ait performans puanı hesaplanacaktır. Betonarme bir bina için yapı performans puanı,

$$
P P=T P+\sum_{i=1}^{n} O_{i} * O P_{i}+Y S P
$$

ifadesi ile hesaplanacaktır. Burada, PP, performans puanı, TP, taban puanı, OP, olumsuzluk puanı, YSP ise yapısal sistem puanı olarak tarif edilmektedir. 
İncelenen bölgedeki binalara yöntemin uygulanması sonucu her bir bina için performans puanı (PP) hesaplanacaktır. Hesaplanan performans puanları büyükten küçüğe doğru sıralanacaktır. Bu şekilde hesaplanan puanların dağılımı kullanılarak bölgeler arasında risk önceliği belirlenebilir [1].

Çalışmada örnek olarak 5 katlı, taşıyıcı sistemi betonarme çerçeve olan bir yapı seçilmiştir (Şekil 2).

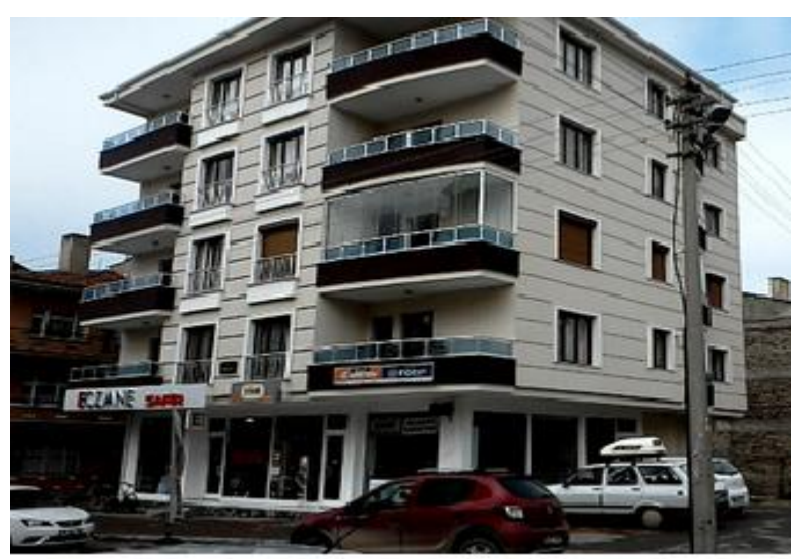

Şekil 2. İncelemeye esas olan bina

Seçilen bu bina için hesaplamalar yapılırken öncelikle binanın mevcut durumu üzerinden farklı zemin grupları için hesaplamalar yapılmıştır. Buradaki amaç zemin türünün, birinci aşama değerlendirmesinde bina performansı üzerindeki etkisini ortaya koymaktır. Tablo 2'de farklı zemin sınıflarına göre hesaplanan yapı performans puanları yer almaktadır.

Betonarme çerçeve sistemlerde zemin sınıfının değişiminin yapı performansını yapının bulunduğu tehlike bölgesinin taban puanı kadar etkilediği görülmektedir.

Tablo 2. Farklı zemin sınıflarına göre BAÇ olması durumunda performans puanları

\begin{tabular}{|c|c|c|c|c|c|c|c|c|c|c|c|c|c|c|c|}
\hline \multirow[t]{2}{*}{ 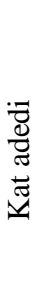 } & \multirow[t]{2}{*}{ 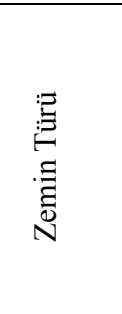 } & \multirow[t]{2}{*}{ 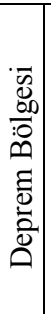 } & \multirow[t]{2}{*}{ 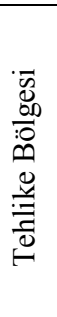 } & \multirow[t]{2}{*}{ 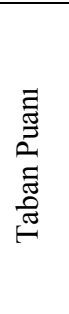 } & $\begin{array}{c}\begin{array}{c}\text { Yapısal } \\
\text { Sistem } \\
\text { Puanı }\end{array} \\
\begin{array}{l}\text { Yapısal } \\
\text { sistem }\end{array}\end{array}$ & 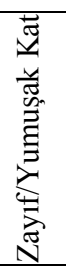 & 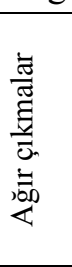 & 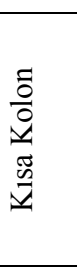 & 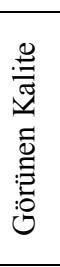 & 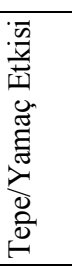 & 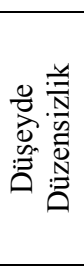 & 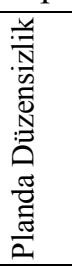 & 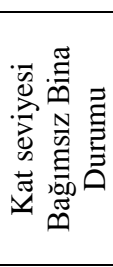 & \multirow[t]{2}{*}{$\begin{array}{c}\text { Olumsuzluk } \\
\text { Puanı } \\
\text { Toplamı }\end{array}$} & \multirow[t]{2}{*}{ 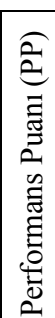 } \\
\hline & & & & & BAÇ & Var & Var & Yok & İyi & Yok & Yok & Yok & Ayrık & & \\
\hline \multirow{7}{*}{5} & Z3/Z4 & 1 & I & 60 & 0 & -30 & -30 & 0 & 0 & 0 & 0 & 0 & 0 & -60 & 0 \\
\hline & $\mathrm{Z1} / \mathrm{Z2}$ & 1 & II & 80 & 0 & -30 & -30 & 0 & 0 & 0 & 0 & 0 & 0 & -60 & 20 \\
\hline & Z3/Z4 & 2 & II & 80 & 0 & -30 & -30 & 0 & 0 & 0 & 0 & 0 & 0 & -60 & 20 \\
\hline & Z1/Z2 & 2 & III & \begin{tabular}{|l|}
110 \\
\end{tabular} & 0 & -30 & -30 & 0 & 0 & 0 & 0 & 0 & 0 & -60 & 50 \\
\hline & $\mathrm{Z3} / \mathrm{Z4}$ & 3 & III & \begin{tabular}{|l|}
110 \\
\end{tabular} & 0 & -30 & -30 & 0 & 0 & 0 & 0 & 0 & 0 & -60 & 50 \\
\hline & Z1/Z2 & 3 & IV & \begin{tabular}{|l|}
135 \\
\end{tabular} & 0 & -30 & -30 & 0 & 0 & 0 & 0 & 0 & 0 & -60 & 75 \\
\hline & $\begin{array}{c}\text { Tüm } \\
\text { zeminler }\end{array}$ & 4 & IV & 135 & 0 & -30 & -30 & 0 & 0 & 0 & 0 & 0 & 0 & -60 & 75 \\
\hline
\end{tabular}


Bir önceki aşamada farklı zemin sınıfları ve betonarme çerçeve sistemler ait hesaplamalar, betonarme çerçeve-perde sistemleri için yenilenmiş̧ir. Betonarme çerçeve-perde sistemleri için yapılan hesaplamalar Tablo 3'te gösterilmiştir.

Tablo 3. Farklı zemin sınıflarına göre BAÇP olması durumunda performans puanları

\begin{tabular}{|c|c|c|c|c|c|c|c|c|c|c|c|c|c|c|c|}
\hline \multirow[t]{2}{*}{ 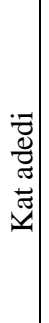 } & \multirow[t]{2}{*}{ 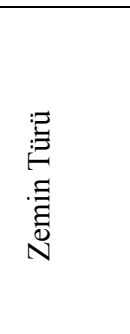 } & \multirow[t]{2}{*}{ 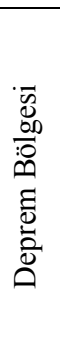 } & \multirow[t]{2}{*}{ 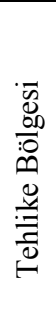 } & \multirow[t]{2}{*}{ 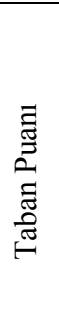 } & $\begin{array}{c}\text { Yapısal } \\
\text { Sistem } \\
\text { Puanı } \\
\begin{array}{c}\text { Yapisal } \\
\text { sistem }\end{array}\end{array}$ & 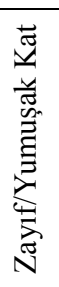 & 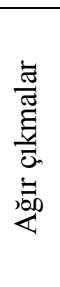 & 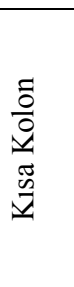 & 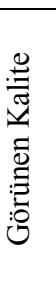 & 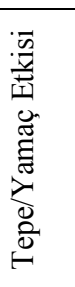 & 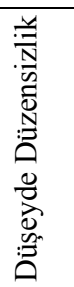 & 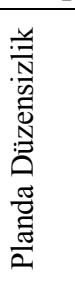 & 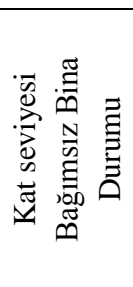 & \multirow[t]{2}{*}{$\begin{array}{c}\text { Olumsuzluk } \\
\text { Puanı } \\
\text { Toplamı }\end{array}$} & \multirow[t]{2}{*}{ 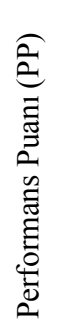 } \\
\hline & & & & & BAÇP & Var & Var & Yok & İyi & Yok & Yok & Yok & Ayrık & & \\
\hline \multirow{7}{*}{5} & Z3/Z4 & 1 & I & 60 & 65 & -30 & -30 & 0 & 0 & 0 & 0 & 0 & 0 & -60 & 65 \\
\hline & $\mathrm{Z} 1 / \mathrm{Z} 2$ & 1 & II & 80 & 65 & -30 & -30 & 0 & 0 & 0 & 0 & 0 & 0 & -60 & 85 \\
\hline & Z3/Z4 & 2 & II & 80 & 65 & $\begin{array}{l}-30 \\
\end{array}$ & $\begin{array}{l}-30 \\
\end{array}$ & 0 & 0 & 0 & 0 & 0 & 0 & $\begin{array}{l}-60 \\
\end{array}$ & 85 \\
\hline & $\mathrm{Z1} / \mathrm{Z} 2$ & 2 & III & 110 & 65 & -30 & -30 & 0 & 0 & 0 & 0 & 0 & 0 & -60 & 115 \\
\hline & Z3/Z4 & 3 & III & 110 & 65 & $\begin{array}{c}-30 \\
\end{array}$ & $\begin{array}{c}-30 \\
\end{array}$ & 0 & 0 & 0 & 0 & 0 & 0 & -60 & 115 \\
\hline & $\mathrm{Z1} / \mathrm{Z} 2$ & 3 & IV & 135 & 65 & -30 & -30 & 0 & 0 & 0 & 0 & 0 & 0 & -60 & 140 \\
\hline & $\begin{array}{c}\text { Tüm } \\
\text { zeminler }\end{array}$ & 4 & IV & 135 & 65 & -30 & -30 & 0 & 0 & 0 & 0 & 0 & 0 & -60 & 140 \\
\hline
\end{tabular}

Yapıların birinci aşama değerlendirilmesi yapılırken önemli faktörlerden biri de yapının görünen kalitesidir. Yapıyı meydana getiren malzemelerin dayanımları yapı performansını doğrudan etkilemektedir. Herhangi bir yapı için yapım aşaması ve sonrasındaki işçilik ve malzeme kalitesine gösterilen özen yapı kalitesini ortaya çıkarmaktadır. Yapının görünen kalitesi için iyi, orta ve kötü olmak üzere üç farklı seçenek sunulmaktadır. Ancak bunun doğru belirlenmesi birçok faktöre bağlidır. Bunların başında yapı ile ilgili bilgileri toplayacak kişinin yapı ile yapı malzemeleri konusunda eğitilmiş ve tecrübeli olması gerekliliği gelir. Yapının tadilat görmesi yapının görsel kalitesi ile ilgili karar vericinin kararını doğrudan etkileyecektir. Ayrıca binalar için kullanılan kaplama malzemeleri de yapının kalitesi ile ilgili doğru kararlar verilmesini engelleyebilmektedir. Bir anlamda makyajlanmış bir binada görsel kaliteyi belirlemek çoğu zaman sağlıklı sonuçlar sağlanmasına imkân tanımamaktadır. İncelenen binada da yapının görsel kalitesinin değişiminin yapı performans puanı üzerindeki etkileri ortaya konulmuştur. Görsel kalitenin orta olması durumunda farklı zemin sınıfları ve betonarme çerçeve sistemler için hesaplanan performans puanları Tablo 4'te verilmiştir.

Farklı zemin sınıfları için taşıyıcı sistemin betonarme çerçeve-perde olması ve görünen kalitenin orta olması durumunda yapı performans puanları Tablo 5'te verilmiştir. Görsel kalitenin kötü olması durumunda farklı zemin sınıfları ve betonarme çerçeve sistemleri için hesaplanan performans puanları Tablo 6' da verilmiştir. Farklı zemin sınıfları için taşıyıcı sistemin betonarme çerçeve-perde olması ve görünen kalitenin kötü olması durumunda yapı performans puanları Tablo 7'de verilmiştir. $\mathrm{Bu}$ çalışmada ayrıca yapının birinci aşama değerlendirilmesinde farklı zemin gruplarında, betonarme çerçeve için incelenen binada tüm olumsuzluk parametrelerinin yapıda bulunması halinde yapı performans puanları Tablo 8'de verilmiştir. Yapının birinci aşama değerlendirilmesinde farklı zemin gruplarında, betonarme çerçeve-perde olması durumunda, binada tüm olumsuzluk parametrelerinin yapıda bulunması halinde yapı performans puanları Tablo 9'da verilmiştir. 
Tablo 4. Farklı zemin sınıflarına göre BAÇ için görünen kalitenin orta olması durumunda performans puanları

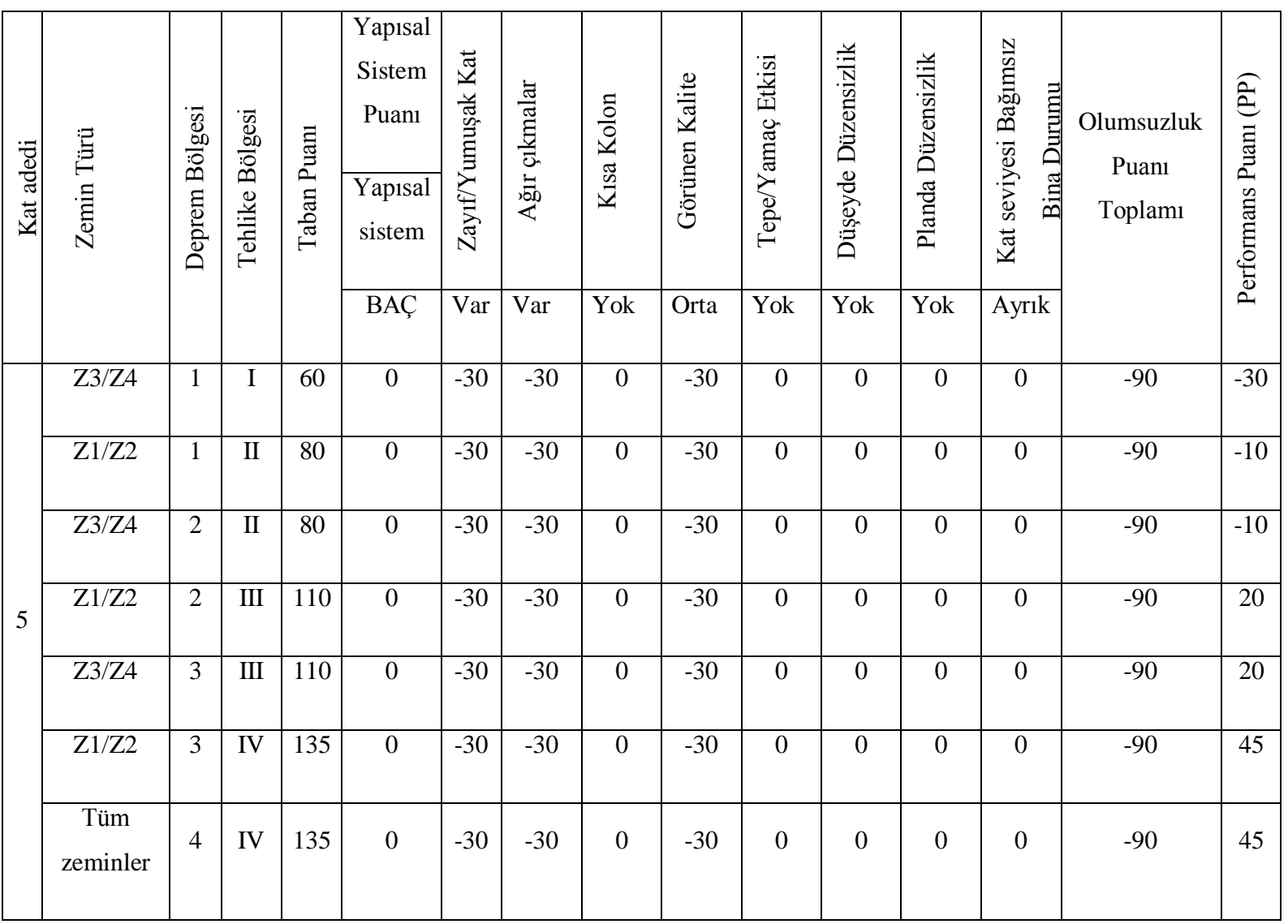

Tablo 5. Farklı zemin sınıflarına göre BAÇP için görünen kalitenin orta olması durumunda performans puanları

\begin{tabular}{|c|c|c|c|c|c|c|c|c|c|c|c|c|c|c|c|}
\hline \multirow[t]{2}{*}{ 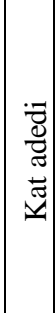 } & \multirow[t]{2}{*}{$\begin{array}{l}\text { : } \\
\text { : } \\
\text { 意 } \\
\text { N }\end{array}$} & \multirow[t]{2}{*}{ 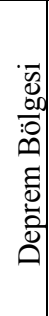 } & \multirow[t]{2}{*}{ 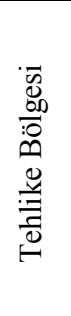 } & \multirow[t]{2}{*}{ 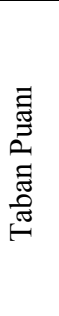 } & $\begin{array}{c}\text { Yapısal } \\
\text { Sistem } \\
\text { Puanı } \\
\text { Yapısal } \\
\text { sistem }\end{array}$ & 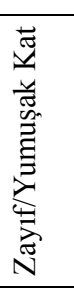 & 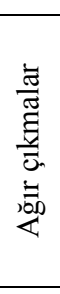 & 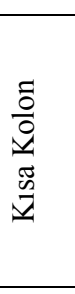 & 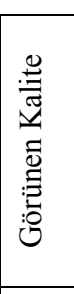 & 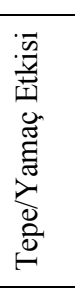 & 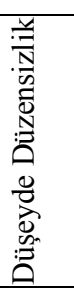 & 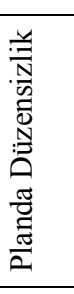 & 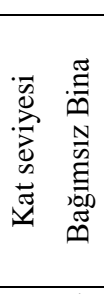 & \multirow[t]{2}{*}{$\begin{array}{c}\text { Olumsuzluk } \\
\text { Puanı } \\
\text { Toplamı }\end{array}$} & \multirow[t]{2}{*}{ 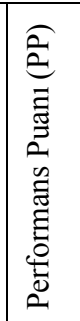 } \\
\hline & & & & & BAÇP & Var & Var & Yok & Orta & Yok & Yok & Yok & Ayrık & & \\
\hline \multirow{7}{*}{5} & Z3/Z4 & 1 & I & 60 & 65 & -30 & -30 & 0 & -30 & 0 & 0 & 0 & 0 & -90 & 35 \\
\hline & $\mathrm{Z} 1 / \mathrm{Z} 2$ & 1 & II & 80 & 65 & -30 & -30 & 0 & \begin{tabular}{|l|}
-30 \\
\end{tabular} & 0 & 0 & 0 & 0 & -90 & 55 \\
\hline & $\mathrm{Z3/Z4}$ & 2 & II & 80 & 65 & -30 & -30 & 0 & \begin{tabular}{|l|}
-30 \\
\end{tabular} & 0 & 0 & 0 & 0 & -90 & 55 \\
\hline & $\overline{Z 1 / Z 2}$ & 2 & III & 110 & 65 & -30 & -30 & 0 & \begin{tabular}{|l|}
-30 \\
\end{tabular} & 0 & 0 & 0 & 0 & -90 & 85 \\
\hline & $\overline{Z 3 / Z 4}$ & 3 & III & 110 & 65 & -30 & -30 & 0 & \begin{tabular}{|l|}
-30 \\
\end{tabular} & 0 & 0 & 0 & 0 & -90 & 85 \\
\hline & $\mathrm{Z} 1 / \mathrm{Z} 2$ & 3 & IV & 135 & 65 & -30 & -30 & 0 & -30 & 0 & 0 & 0 & 0 & \begin{tabular}{|c|}
-90 \\
\end{tabular} & 110 \\
\hline & $\begin{array}{c}\text { Tüm } \\
\text { zeminler }\end{array}$ & 4 & IV & 135 & 65 & -30 & -30 & 0 & -30 & 0 & 0 & 0 & 0 & -90 & 110 \\
\hline
\end{tabular}


Tablo 6. Farklı zemin sınıflarına göre BAÇ için görünen kalitenin kötü olması durumunda performans puanları

\begin{tabular}{|c|c|c|c|c|c|c|c|c|c|c|c|c|c|c|c|}
\hline \multirow[t]{2}{*}{ 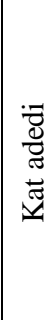 } & \multirow[t]{2}{*}{ 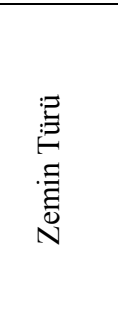 } & \multirow[t]{2}{*}{ 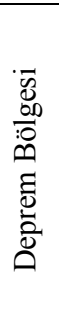 } & \multirow[t]{2}{*}{ 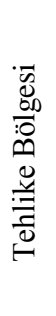 } & \multirow[t]{2}{*}{ 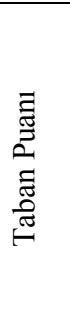 } & $\begin{array}{c}\text { Yapısal } \\
\text { Sistem } \\
\text { Puanı } \\
\text { Yapısal } \\
\text { sistem }\end{array}$ & 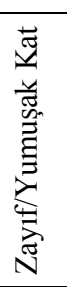 & 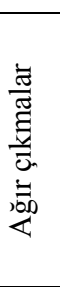 & 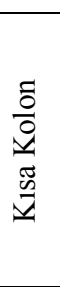 & 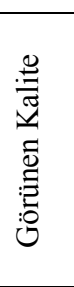 & 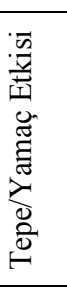 & 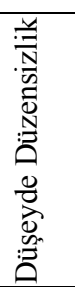 & 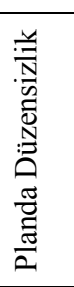 & 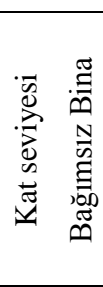 & \multirow[t]{2}{*}{$\begin{array}{l}\text { Olumsuzluk } \\
\text { Puanı } \\
\text { Toplamı }\end{array}$} & 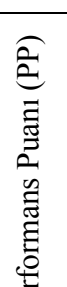 \\
\hline & & & & & BAÇ & Var & Var & Yok & Kötü & Yok & Yok & Yok & Ayrık & & 2 \\
\hline \multirow{7}{*}{5} & Z3/Z4 & 1 & I & 60 & 0 & -30 & -30 & 0 & -60 & 0 & 0 & 0 & 0 & -120 & -60 \\
\hline & $\mathrm{Z1/Z2}$ & 1 & II & 80 & 0 & -30 & -30 & 0 & -60 & 0 & 0 & 0 & 0 & -120 & -40 \\
\hline & $\mathrm{Z} 3 / \mathrm{Z} 4$ & 2 & II & 80 & 0 & -30 & -30 & 0 & -60 & 0 & 0 & 0 & 0 & -120 & -40 \\
\hline & $\mathrm{Z} 1 / \mathrm{Z} 2$ & 2 & III & 110 & 0 & -30 & -30 & 0 & -60 & 0 & 0 & 0 & 0 & -120 & -10 \\
\hline & $\overline{Z Z 3 / Z 4}$ & 3 & III & 110 & 0 & -30 & -30 & 0 & -60 & 0 & 0 & 0 & 0 & -120 & -10 \\
\hline & $\mathrm{Z} 1 / \mathrm{Z} 2$ & 3 & IV & 135 & 0 & -30 & -30 & 0 & -60 & 0 & 0 & 0 & 0 & -120 & 15 \\
\hline & $\begin{array}{c}\text { Tüm } \\
\text { zeminler }\end{array}$ & 4 & IV & 135 & 0 & -30 & -30 & 0 & -60 & 0 & 0 & 0 & 0 & -120 & 15 \\
\hline
\end{tabular}

Tablo 7. Farklı zemin sınıflarına göre BAÇP için görünen kalitenin kötü olması durumunda performans puanlar1

\begin{tabular}{|c|c|c|c|c|c|c|c|c|c|c|c|c|c|c|c|}
\hline \multirow[t]{2}{*}{ 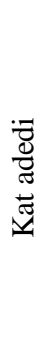 } & \multirow[t]{2}{*}{ 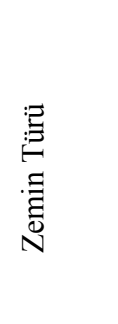 } & \multirow[t]{2}{*}{ 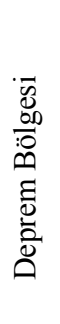 } & \multirow[t]{2}{*}{ 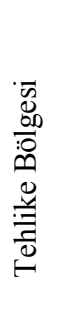 } & \multirow[t]{2}{*}{ 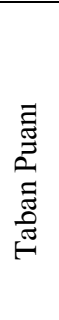 } & $\begin{array}{c}\text { Yapısal } \\
\text { Sistem } \\
\text { Puanı } \\
\begin{array}{c}\text { Yapısal } \\
\text { sistem }\end{array}\end{array}$ & 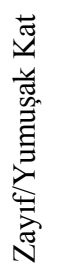 & 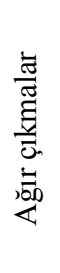 & 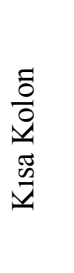 & 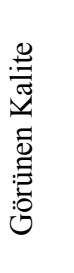 & 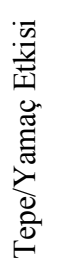 & 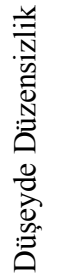 & 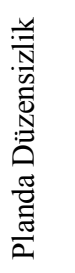 & 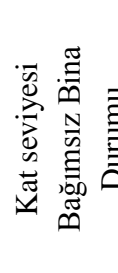 & \multirow[t]{2}{*}{$\begin{array}{l}\text { Olumsuzluk } \\
\text { Puanı } \\
\text { Toplamı }\end{array}$} & \multirow[t]{2}{*}{ 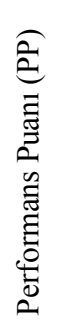 } \\
\hline & & & & & BAÇP & Var & Var & Yok & Kötü & Yok & Yok & Yok & Ayrık & & \\
\hline & Z3/Z4 & 1 & I & 60 & 65 & -30 & -30 & 0 & -60 & 0 & 0 & 0 & 0 & -120 & 5 \\
\hline & $\mathrm{Z1} 1 / \mathrm{Z} 2$ & 1 & II & 80 & 65 & -30 & -30 & 0 & -60 & 0 & 0 & 0 & 0 & -120 & 25 \\
\hline & Z3/Z4 & 2 & II & 80 & 65 & -30 & -30 & 0 & -60 & 0 & 0 & 0 & 0 & -120 & 25 \\
\hline 5 & $\overline{\mathrm{Z} 1 / \mathrm{Z} 2}$ & 2 & III & 110 & 65 & -30 & -30 & 0 & -60 & 0 & 0 & 0 & 0 & -120 & 55 \\
\hline & $\begin{array}{l}\mathrm{Z} 3 / \mathrm{Z} 4 \\
\end{array}$ & 3 & III & 110 & 65 & $\begin{array}{l}-30 \\
\end{array}$ & $\begin{array}{l}-30 \\
\end{array}$ & 0 & -60 & 0 & 0 & 0 & 0 & -120 & 55 \\
\hline & Z1/Z2 & 3 & IV & 135 & 65 & -30 & -30 & 0 & -60 & 0 & 0 & 0 & 0 & -120 & 80 \\
\hline & $\begin{array}{c}\text { Tüm } \\
\text { zeminler }\end{array}$ & 4 & IV & 135 & 65 & -30 & -30 & 0 & -60 & 0 & 0 & 0 & 0 & -120 & 80 \\
\hline
\end{tabular}


Tablo 8. Farklı zemin sınıflarına göre BAÇ için tüm olumsuzlukların bulunması durumunda performans puanlar1

\begin{tabular}{|c|c|c|c|c|c|c|c|c|c|c|c|c|c|c|c|}
\hline \multirow[t]{2}{*}{ 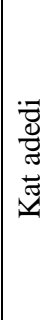 } & \multirow[t]{2}{*}{ 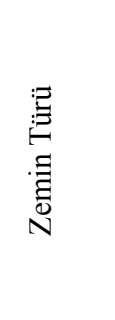 } & \multirow[t]{2}{*}{ 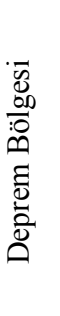 } & \multirow[t]{2}{*}{ 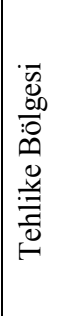 } & \multirow[t]{2}{*}{ 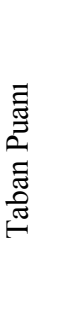 } & $\begin{array}{c}\text { Yapısal } \\
\text { Sistem } \\
\text { Puanı } \\
\text { Yapısal } \\
\text { sistem } \\
\end{array}$ & 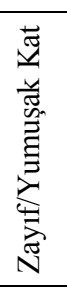 & 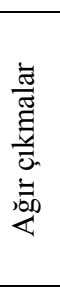 & 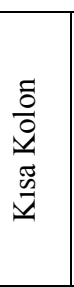 & 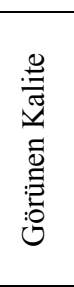 & 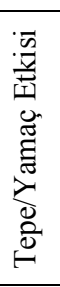 & 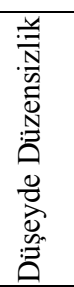 & 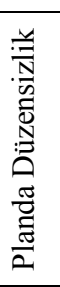 & 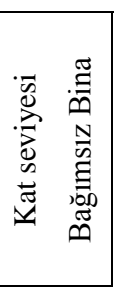 & \multirow[t]{2}{*}{$\begin{array}{l}\text { Olumsuzluk } \\
\text { Puanı } \\
\text { Toplamı }\end{array}$} & 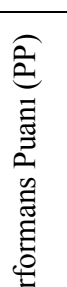 \\
\hline & & & & & BAÇ & Var & Var & Var & Kötü & Var & Var & Var & Kenar & & $\stackrel{\vec{D}}{\Omega}$ \\
\hline \multirow{7}{*}{5} & Z3/Z4 & 1 & I & 60 & 0 & -30 & -30 & -5 & -60 & -3 & -15 & -10 & -15 & -168 & 108 \\
\hline & $\mathrm{Z1} / \mathrm{Z} 2$ & 1 & II & 80 & 0 & -30 & $\begin{array}{c}-30 \\
\end{array}$ & -5 & -60 & -3 & -15 & $\begin{array}{c}-10 \\
\end{array}$ & -15 & -168 & -88 \\
\hline & Z3/Z4 & 2 & II & 80 & 0 & -30 & $\begin{array}{c}-30 \\
\end{array}$ & -5 & -60 & -3 & -15 & $\begin{array}{c}-10 \\
\end{array}$ & -15 & -168 & -88 \\
\hline & $\mathrm{Z1} / \mathrm{Z} 2$ & 2 & III & 110 & 0 & -30 & -30 & -5 & -60 & -3 & -15 & -10 & -15 & -168 & -58 \\
\hline & Z3/Z4 & 3 & III & 110 & 0 & -30 & -30 & -5 & -60 & -3 & -15 & -10 & -15 & -168 & -58 \\
\hline & $\mathrm{Z1/Z2}$ & 3 & IV & 135 & 0 & -30 & -30 & -5 & -60 & -3 & -15 & -10 & -15 & -168 & -33 \\
\hline & $\begin{array}{c}\text { Tüm } \\
\text { zeminler }\end{array}$ & 4 & IV & 135 & 0 & -30 & -30 & -5 & -60 & -3 & -15 & -10 & -15 & -168 & -33 \\
\hline
\end{tabular}

Tablo 9. Farklı zemin sınıflarına göre BAÇP için tüm olumsuzlukların olması durumunda performans puanlar1

\begin{tabular}{|c|c|c|c|c|c|c|c|c|c|c|c|c|c|c|c|}
\hline \multirow[t]{2}{*}{ 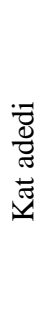 } & \multirow[t]{2}{*}{ 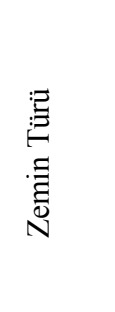 } & \multirow[t]{2}{*}{ 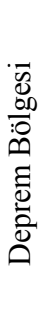 } & \multirow[t]{2}{*}{ 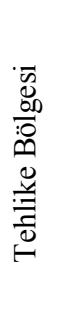 } & \multirow[t]{2}{*}{ 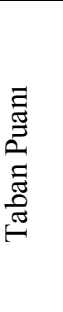 } & $\begin{array}{c}\text { Yapısal } \\
\text { Sistem } \\
\text { Puanı } \\
\text { Yapısal } \\
\text { sistem }\end{array}$ & 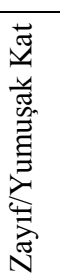 & 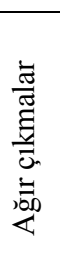 & 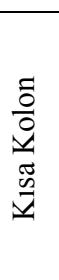 & 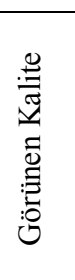 & 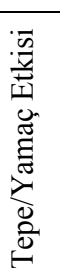 & 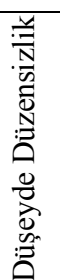 & 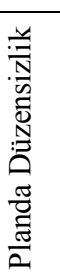 & 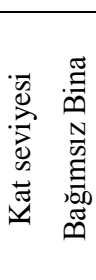 & \multirow[t]{2}{*}{$\begin{array}{c}\text { Olumsuzluk } \\
\text { Puanı } \\
\text { Toplamı }\end{array}$} & \multirow[t]{2}{*}{ 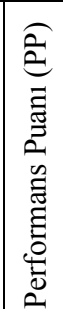 } \\
\hline & & & & & BAÇP & Var & Var & Var & Kötü & Var & Var & Var & Kenar & & \\
\hline \multirow{7}{*}{5} & $\mathrm{Z} 3 / \mathrm{Z} 4$ & 1 & I & 60 & 65 & -30 & -30 & -5 & -60 & -3 & -15 & -10 & -15 & -168 & -43 \\
\hline & $\mathrm{Z} 1 / \mathrm{Z} 2$ & 1 & II & 80 & 65 & -30 & -30 & -5 & -60 & -3 & -15 & -10 & -15 & -168 & -23 \\
\hline & $\begin{array}{l}\mathrm{Z} 3 / \mathrm{Z} 4 \\
\end{array}$ & 2 & II & 80 & 65 & -30 & $\begin{array}{l}-30 \\
\end{array}$ & -5 & -60 & -3 & -15 & -10 & -15 & $\begin{array}{l}-168 \\
\end{array}$ & -23 \\
\hline & $\mathrm{Z1/Z2}$ & 2 & III & 110 & 65 & -30 & -30 & -5 & $\begin{array}{l}-60 \\
\end{array}$ & -3 & -15 & -10 & -15 & -168 & 7 \\
\hline & Z3/Z4 & 3 & III & 110 & 65 & -30 & -30 & -5 & -60 & -3 & -15 & -10 & -15 & -168 & 7 \\
\hline & $\mathrm{Z1/Z2}$ & 3 & IV & 135 & 65 & -30 & -30 & -5 & -60 & -3 & -15 & -10 & -15 & -168 & 32 \\
\hline & $\begin{array}{c}\text { Tüm } \\
\text { zeminler }\end{array}$ & 4 & IV & 135 & 65 & -30 & -30 & -5 & -60 & -3 & -15 & -10 & -15 & -168 & 32 \\
\hline
\end{tabular}

Yapının birinci aşama değerlendirilmesinde farklı zemin gruplarında, betonarme çerçeve olması durumunda ve binada hiçbir olumsuzluk parametresinin bulunmadığı durumda hesaplanan yapı performans puanları Tablo 10'da ve betonarme çerçeve-perde olması durumu ise Tablo 11'de verilmiştir. 
Tablo 10. Farklı zemin sınıflarına göre BAÇ için hiç olumsuzluk bulunmaması durumunda performans puanları

\begin{tabular}{|c|c|c|c|c|c|c|c|c|c|c|c|c|c|c|c|}
\hline \multirow[t]{2}{*}{ 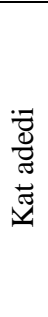 } & \multirow[t]{2}{*}{ 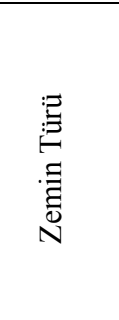 } & \multirow[t]{2}{*}{ 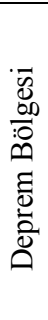 } & \multirow[t]{2}{*}{ 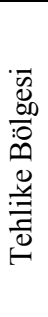 } & \multirow[t]{2}{*}{ 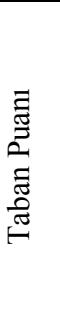 } & $\begin{array}{c}\text { Yapısal } \\
\text { Sistem } \\
\text { Puanı } \\
\text { Yapısal } \\
\text { sistem } \\
\end{array}$ & 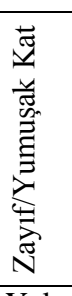 & 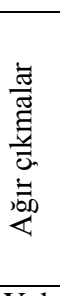 & 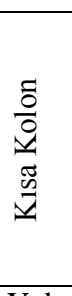 & 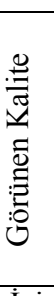 & 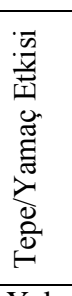 & 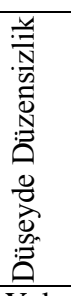 & 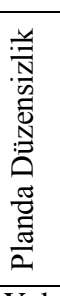 & 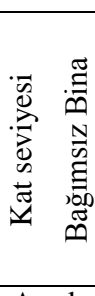 & \multirow[t]{2}{*}{$\begin{array}{c}\text { Olumsuzluk } \\
\text { Puanı } \\
\text { Toplamı }\end{array}$} & \multirow[t]{2}{*}{ 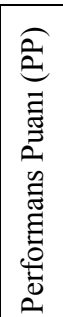 } \\
\hline & & & & & BAÇ & Yok & Yok & Yok & İyi & Yok & Yok & Yok & Ayrık & & \\
\hline \multirow{7}{*}{5} & Z3/Z4 & 1 & I & 60 & 0 & 0 & 0 & 0 & 0 & 0 & 0 & 0 & 0 & 0 & 60 \\
\hline & $\mathrm{Z} 1 / \mathrm{Z} 2$ & 1 & II & 80 & 0 & 0 & 0 & 0 & 0 & 0 & 0 & 0 & 0 & 0 & 80 \\
\hline & Z3/Z4 & 2 & II & 80 & 0 & 0 & 0 & 0 & 0 & 0 & 0 & 0 & 0 & 0 & 80 \\
\hline & $\mathrm{Z} 1 / \mathrm{Z} 2$ & 2 & III & 110 & 0 & 0 & 0 & 0 & 0 & 0 & 0 & 0 & 0 & 0 & 110 \\
\hline & $\mathrm{Z} 3 / \mathrm{Z4}$ & 3 & III & 110 & 0 & 0 & 0 & 0 & 0 & 0 & 0 & 0 & 0 & 0 & 110 \\
\hline & $\mathrm{Z} 1 / \mathrm{Z} 2$ & 3 & IV & 135 & 0 & 0 & 0 & 0 & 0 & 0 & 0 & 0 & 0 & 0 & 135 \\
\hline & $\begin{array}{c}\text { Tüm } \\
\text { zeminler }\end{array}$ & 4 & IV & 135 & 0 & 0 & 0 & 0 & 0 & 0 & 0 & 0 & 0 & 0 & 135 \\
\hline
\end{tabular}

Tablo 11. Farklı zemin sınıflarına göre BAÇP için hiç olumsuzluk bulunmaması durumunda performans puanlar1

\begin{tabular}{|c|c|c|c|c|c|c|c|c|c|c|c|c|c|c|c|}
\hline \multirow[t]{2}{*}{ 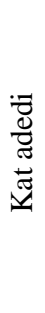 } & \multirow[t]{2}{*}{ 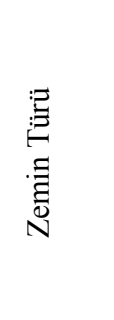 } & \multirow[t]{2}{*}{ 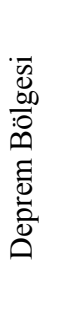 } & \multirow[t]{2}{*}{ 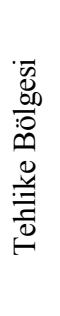 } & \multirow[t]{2}{*}{ 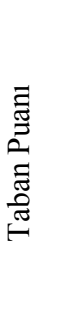 } & $\begin{array}{c}\text { Yapısal } \\
\text { Sistem } \\
\text { Puanı } \\
\text { Yapısal } \\
\text { sistem }\end{array}$ & 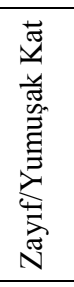 & 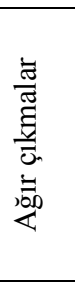 & 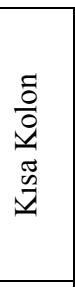 & 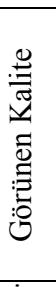 & 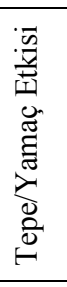 & 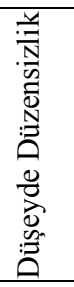 & 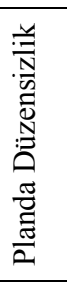 & 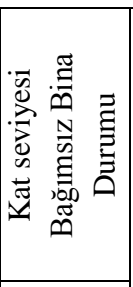 & \multirow[t]{2}{*}{$\begin{array}{l}\text { Olumsuzluk } \\
\text { Puanı } \\
\text { Toplamı }\end{array}$} & \multirow[t]{2}{*}{ 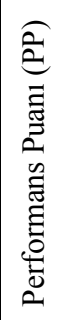 } \\
\hline & & & & & BAÇP & Yok & Yok & Yok & İyi & Yok & Yok & Yok & Ayrrk & & \\
\hline \multirow{7}{*}{5} & Z3/Z4 & 1 & I & 60 & 65 & 0 & 0 & 0 & 0 & 0 & 0 & 0 & 0 & 0 & 125 \\
\hline & Z1/Z2 & 1 & II & 80 & 65 & 0 & 0 & 0 & 0 & 0 & 0 & 0 & 0 & 0 & 145 \\
\hline & Z3/Z4 & 2 & II & 80 & 65 & 0 & 0 & 0 & 0 & 0 & 0 & 0 & 0 & 0 & 145 \\
\hline & $\mathrm{Z1} / \mathrm{Z} 2$ & 2 & III & 110 & 65 & 0 & 0 & 0 & 0 & 0 & 0 & 0 & 0 & 0 & 175 \\
\hline & Z3/Z4 & 3 & III & 110 & 65 & 0 & 0 & 0 & 0 & 0 & 0 & 0 & 0 & 0 & 175 \\
\hline & $\mathrm{Z1/Z2}$ & 3 & IV & 135 & 65 & 0 & 0 & 0 & 0 & 0 & 0 & 0 & 0 & 0 & 200 \\
\hline & $\begin{array}{c}\text { Tüm } \\
\text { zeminler }\end{array}$ & 4 & IV & 135 & 65 & 0 & 0 & 0 & 0 & 0 & 0 & 0 & 0 & 0 & 200 \\
\hline
\end{tabular}

\section{Sonuçlar}

Mevcut yapı stokunun çok olması, bu tür yapılarla ilgili değerlendirmelerin zaman ve teknik eleman eksikliğinden dolayı çok gerçekçi yapılamayabileceği sonucunu ortaya çıkarmaktadır. $\mathrm{Bu}$ değerlendirmelerin bilimsel olarak sağlıklı sonuçlar verebilmesi için hızlı değerlendirme yöntemlerine ihtiyaç duyulmaktadır. Bu ihtiyaca binaen Çevre ve Şehircilik Bakanlığı tarafından riskli binaların tespit esasları belirlenmiştir. Bu tespit esaslarında yer alan değerlendirme yöntemlerinden biri de 
birinci aşama değerlendirme yöntemidir. Yapının deprem etkisindeki davranışını etkileyecek bazı parametrelerin yapı içine girmeden kısmen de yapı içerisinden elde edilen bilgiler ile belirlenmesi mümkündür. Elde edilen parametrelerin her biri için bir puan tarif edilmekte, bu puanlar arasındaki ilişkiden faydalanılarak bina performans puanı hesaplanmaktadır. Bu hesaplama ile binalarda risk öncellikleri belirlenmektedir.

Bu çalışmada 2013 yılında yürürlüğe giren riskli yapıların tespit edilmesine ilişkin esaslar kısmında yer alan, birinci aşama değerlendirme yöntemi kullanılarak mevcut beş katlı bir betonarme yapının zemin sınıfları, taşıyıcı sistem türü ve görünen yapı kalitesi parametreleri değişken olarak seçilmiş ve bu değişkenlere göre bina performans puanları hesaplanmıştır. Hesaplanan performans puanları karşılaştırılmış ve seçilen değişkenlerin yapı performans puanları üzerindeki etkileri yorumlanmıştır.

Yapıların deprem güvenliklerinin belirlenmesinde dikkate alınması gereken parametrelerden biri yerel zemin koşullarıdır. Yerel zemin koşullarının değişimi yapı performansını betonarme çerçeve sistemlerinde taban puanı kadar, betonarme çerçeve-perde sistemlerinde taban puanı ile taşıyıcı sistem puanlarının toplamı kadar etkilemektedir.

Yapıların birinci aşama değerlendirilmesi yapılırken önemli faktörlerden biri de yapının görsel kalitesidir. Görsel kalitenin yap1 performans puanını ciddi bir şekilde etkilediği tablolardan görülmektedir. Dolayısıyla yapı görsel kalitesinin doğru tespit edilmesi için karar vericilerin eğitimi ve tecrübesi ile doğrudan ilgilidir.

Birinci aşama değerlendirmede dikkate alınan olumsuzluk parametrelerinin hepsinin yapıda bulunması yapı performans puanının oldukça düşük değerlerde olmasına yol açmıştır. Bu da tasarım yapılırken yapılarda olumsuzlukların dikkate alınması gerektiği sonucunu doğurmuştur. Yapıda olumsuzluk parametrelerinin hiç bulunmaması yapı performans puanlarını yukarı noktalara çekmiştir. Kısacası yapıların deprem etkileri altında savunmasızlığı arttıkça, yapıda oluşabilecek hasar miktarının artacağı anlamını taşımaktadır.

Düşük riskli çıkan binaların deprem yönetmeliğine uygun olup olmadığı kesin bir dille söylenemez. Yukarıda belirtildiği gibi bu sadece birinci aşama değerlendirmedir. Dolayısıyla kesin sonuçlar ancak ileri analiz yöntemleri sonucunda ortaya çıkacaktır. Bu yöntem sadece ikinci aşama değerlendirme yönteminde incelenecek binaların önceliğinin belirlenmesi amacını taşımaktadır.

\section{Kaynaklar}

1. Riskli Bina Tespit Esasları, 2013. Afet Riski Altındaki Alanların Dönüştürülmesi Hakkında Kanunun Uygulama Yönetmeliğinde Değişiklik Yapılmasına Dair Yönetmelik. Çevre ve Şehircilik Bakanlığ 1 .

2. Işık E, 2013. Bitlis İli Yapı Stokunun Birinci Kademe (Sokak Tarama Yöntemi İle) Değerlendirilmesi. Süleyman Demirel Üniversitesi, Fen Bilimleri Enstitüsü Dergisi, 17 (1): 173 178.

3. Sucuoğlu H, 2007. Kentsel Yapı Stoklarında Deprem Risklerinin Sokaktan Tarama Yöntemi İle Belirlenmesi. 6. Ulusal Deprem Mühendisliği Konferans1, İstanbul, s: 267-284.

4. Türk Deprem Yönetmeliği (DBYBHY 2007), Deprem Bölgelerinde Yapılacak Binalar Hakkında Yönetmelik, T. C. Çevre ve Şehircilik Bakanlığı, Afet İşleri Genel Müdürlüğü, Deprem Araştırma Dairesi.

5. Çevre ve Şehircilik Bakanlığı, 2015.

http://www.csb.gov.tr/db/altyapi/editordosya/Gun\%201_Ders\%202_RiskliBinaTespitEsaslari(3).pd f (Erişim tarihi: 21.07.2015). 
6. Çağatay İH, Güzeldağ S, 2002. Yeni Deprem Yönetmeliği (TDY-98) SAP2000N Uygulamaları. Birsen Yayınevi, İstanbul.

7. Tezcan S, Yazıcı A, Özdemir Z, Erkal A, 2007. Zayıf Kat-Yumuşak Kat Düzensizliği. 6. Ulusal Deprem Mühendisliği Konferans1, İstanbul, s: 339-350.

8. Tokgöz H, Bayraktar H, 2015. Düzce İli Kaynaşlı İlçesinde Riskli Binaların Tespitinde Sokak Taraması Yönteminin Uygulanması. Düzce Üniversitesi Bilim ve Teknoloji Dergisi, 3 (1): 107116.

9. Özmen G, 2001. Plan Geometrisinin Burulma Düzensizliğine Etkisi. Türkiye Mühendislik Haberleri, 46: 37-41.

10. Deprem Şurası, 2004. T.C. Bayındırlık ve İskân Bakanlığı (Mülga), Komisyon Raporları, Ankara, $1-580$.

11. İnan T, Korkmaz K, 2012. Düşey Doğrultudaki Yapı Düzensizliklerinin İncelenmesi. Erciyes Üniversitesi Fen Bilimleri Enstitüsü Dergisi, 28 (3): 240-248.

12. Özcebe G, 2004. Deprem Güvenliğinin Saptanması İçin Yöntemler Geliştirilmesi Sonuç Raporu. TÜBİTAK İÇTAG YMAÜ 1574 Nolu Araştırma Projesi, Ankara.

13. Borcherdt RD, 1990. Influence of Local Geology in the San Francisco Bay Region California on Ground Motions Generated 1990, by the Loma Prieta Earthquake of October 17, 1989. Proceedings of International Symposium on Safety of Urban Life and Facilities, November 1-2, 1-35, Tokyo, Japan.

Geliş Tarihi: 22/07/2015

Kabul Tarihi: 14/09/2015 